\title{
Energy, Exergy and Anergy Analysis of a Solar Desiccant Cooling System
}

\author{
M. Mujahid Rafique, P. Gandhidasan, Luai M. Al-Hadhrami, and Shafiqur Rehman
}

\begin{abstract}
Some alternative and cost effective approaches are needed for space cooling of buildings in order to resolve environmental and economic issues. Desiccant cooling is one of the alternative to conventional air conditioning systems which can solve many problems related to air conditioning. In this paper a method is developed for energy, exergy and anergy analysis of the desiccant cooling system operating on ventilation cycle. Both exergy and energy analysis are usually applied in parallel in order to find the rational use of energy and to determine the individual performances of each component. The transport of exergy between the system components and destructions of exergy accompanied with each component of the system are determined using average parameters calculated from theoretical analysis. The effect of ratio between regeneration to process air flow rate and temperature of regeneration on system performance has been studied too. The results shows that desiccant wheel and solar collector shares the major part of the exergy destruction (about 65\%). The upper theoretical limit of system performance can be determined by carrying both exergy and energy analysis which cannot be determined by carrying energy analysis alone. The analysis shows the direction for exergy destruction/anergy minimization by identifying and quantifying the sites with exergy losses.
\end{abstract}

Index Terms-Energy, exergy, anergy, desiccant cooling, solar energy, exergy efficiency.

\section{INTRODUCTION}

Heat energy is required for the operation of desiccant cooling units and this technology is found to be a suitable and cost effective alternative to conventional cooling systems. The system mainly consists of a desiccant dehumidifier, heat recovery wheel, heating source and evaporative coolers. In its operation the hot and humid air is dehumidified after passing through the desiccant dehumidifier and then this dry air is somewhat cooled down in heat recovery wheel. The evaporative coolers are used to achieve the required indoor air supply conditions. The system may operate on an open cycle (ventilation or recirculation) or on a closed cycle. For the operation to be continuous, heat is supplied to regenerate the desiccant wheel and for this purpose renewable energies such as; solar, biomass, waste heat etc. can be used effectively.

The system is simple and can operate on a satisfactory

Manuscript received September 30, 2014; revised January 18, 2015

M. Mujahid Rafique is with the Department of Mechanical Engineering, King Fahd University of Petroleum and Minerals, Dhahran 31261, Saudi Arabia (e-mail: mujahid_ep2008@yahoo.com)

P. Gandhidasan was with Department of Mechanical Engineering, King Fahd University of Petroleum and Minerals, Dhahran 31261, Saudi Arabia.

Luai M. Al-Hadhrami and Shafiqur Rehman are with the Center for Engineering Research, Research Institute, King Fahd University of Petroleum and Minerals, Dhahran 31261, Saudi Arabia. thermal COP. Many studies investigated the performance of desiccant cooling systems. Some of them investigated and optimized the operating parameters for the individual component i.e. desiccant dehumidifier and others dealt with the whole system [1], [2]. Krishna and Murthy [3] and Jain $e t$ al. [4] investigated the performance of open cycle desiccant cooling system. Mavroudaki et al. [5] conducted a feasible study of desiccant cooling system for conditions of Europe and United States of America.

Many researchers also conducted the system analysis based upon second law. Lavan et al. [6] presented second law analysis of the system and observed the performance of its individual components and evaluated the reversible $\mathrm{COP}$ of the system. Maclaine-cross [7] proposed a desiccant cooling system with infinite COP. Pons and Kodama [8] investigated the variations of entropy generation w.r.t certain operating parameters.

Exergy analysis of any energy system is key factor for optimization and evaluation of its performance. The basic purpose of this analysis is usually to maximize the system overall performance by identifying the reasons/sites for destruction of exergy. Many researchers discussed the methodology and basic principles of exergy analysis [9], [10]. The exergy analysis can be done for the whole system or for a complex system this can be done for each component separately [11], [12].

Dincer et al. [13] carried an exergy analysis of HVAC system which includes psychrometric processes. The relations for exergy efficiency, entropy generation and energy were developed for air conditioning systems which are commonly used including cooling, cooling with dehumidification, heating with dehumidification and evaporative cooling.

\section{Concept of Exergy, Anergy and Energy}

The potential of a system to do work with reference to its dead state is defined as the exergy of that system. The dead state occurs when equilibrium occurs between the system and the environment. The energy which has no work potential and is rejected to the environment is referred to as anergy or exergy lost.

In general,

$$
\text { Energy }=\text { Exergy }+ \text { Anergy }
$$

The Specific exergy, energy and anergy for a flow stream disregarding potential and kinetic energies is given as

$$
\begin{gathered}
\text { Exergy }=E=\left[\left(h-h_{o}\right)-T_{o}\left(s-s_{o}\right)\right] \\
\text { Energy }=\left[\left(h-h_{o}\right)\right]
\end{gathered}
$$




$$
\text { Anergy }=\left[T_{o}\left(s-S_{o}\right)\right]
$$

The thermodynamics first and second law can be modified using the concept of exergy and anergy as

1) In a process, the value of total sum of anergy and exergy remains constant.

2) The exergy decreases and anergy increases in any real process at the same rate of entropy generation.

3) The anergy has no work potential i.e. cannot be converted to exergy.

4) At the dead state all kind of energy is anergy (have no work potential).

Some differences between exergy and energy efficiency are listed in Table I.

\begin{tabular}{cc} 
TABLE I: DIFFERENCES BETWEEN EXERGY AND ENERGY EFFICIENCY \\
\hline \hline Energy Efficiency & Exergy Efficiency \\
\hline $\begin{array}{c}\text { Defined by thermodynamics first } \\
\text { law. }\end{array}$ & $\begin{array}{c}\text { Defined by thermodynamics } \\
\text { second law. }\end{array}$ \\
\hline $\begin{array}{c}\text { Always greater than } 0 \text { but in some } \\
\text { cases can be greater than } 1 \text { i.e. heat } \\
\text { pumps etc. }\end{array}$ & Always between 0 and 1. \\
\hline Not always homogenous terms. & Homogenous terms. \\
\hline \hline
\end{tabular}

\section{ANALysis OF A SOLAR DESICCANT COOLING SYSTEM}

\section{A. Energy Analysis}

The basic desiccant cooling cycle operating on ventilation mode is shown in Fig. 1. For the energy balances on a system, the first law of thermodynamics is usually referred which says that energy of the system is conserved. The coefficient of performance for the system which is a heat driven process is defined as

$$
C O P=\frac{\dot{Q_{c}}}{\dot{Q}_{r}}
$$

All the state numbers are referred to Fig. 1.

The effectiveness of the heat recovery wheel (HRW) and the desiccant wheel (DW) for different values of process and regeneration mass flow rates is expressed as

$$
\begin{array}{r}
\varepsilon_{H R W}=\frac{\dot{m}_{1}\left(T_{2}-T_{3}\right)}{\dot{m}_{2}\left(T_{2}-T_{6}\right)} \\
\varepsilon_{D W}=\frac{\dot{m}_{1}\left(T_{2}-T_{1}\right)}{\dot{m}_{2}\left(T_{8}-T_{1}\right)}
\end{array}
$$

The effectiveness of two evaporative coolers (EC) evaporative coolers can be expressed as

$$
\begin{gathered}
\varepsilon_{E C, \mathrm{p}}=\frac{T_{3}-T_{4}}{T_{3}-T_{w 3}} \\
\varepsilon_{E C, \mathrm{r}}=\frac{T_{5}-T_{6}}{T_{5}-T_{w 5}}
\end{gathered}
$$

\section{B. Exergy Analysis}

For a flow stream, disregarding the kinetic and potential energies, rate of exergy can be written as

$$
\dot{E}=\dot{m} E=\dot{m}\left[\left(h-h_{o}\right)-T_{o}\left(s-s_{o}\right)\right]
$$

The anergy also called as exergy destruction, and exergy efficiency for all components of the system will be defined now. The exergy destruction rate can be obtained from rate of entropy generation $\left(S_{g e n}\right)$

$$
\dot{E}_{\text {destruction }}=T_{o} \dot{S}_{\text {gen }}
$$

$T_{o}$ is the dead state temperature which in this case represents $T_{1}$. The rate of entropy generation for desiccant wheel, heat recovery wheel, evaporative coolers and solar collector is given by

$$
\dot{S}_{g e n, D W}=\dot{m}_{1}\left[s_{2}-s_{1}\right]+\dot{m}_{2}\left[s_{9}-s_{8}\right]
$$

$$
\dot{S}_{g e n, \mathrm{HRW}}=\dot{m}_{1}\left[s_{3}-s_{2}\right]+\dot{m}_{2}\left[s_{7}-s_{6}\right]
$$

$$
\dot{S}_{g e n, \text { EC } 1}=\dot{m}_{1}\left[s_{4}-s_{3}\right]+\dot{m}_{w, p}\left[s_{w}\right]
$$

$$
\dot{S}_{g e n, \text { EC } 2}=\dot{m}_{2}\left[S_{6}-S_{5}\right]+\dot{m}_{w, \mathrm{r}}\left[S_{w}\right]
$$

$$
\dot{S}_{g e n, S C}=\dot{m}_{2}\left[s_{8}-s_{7}\right]-\frac{\dot{Q}_{r}}{T_{8}}
$$
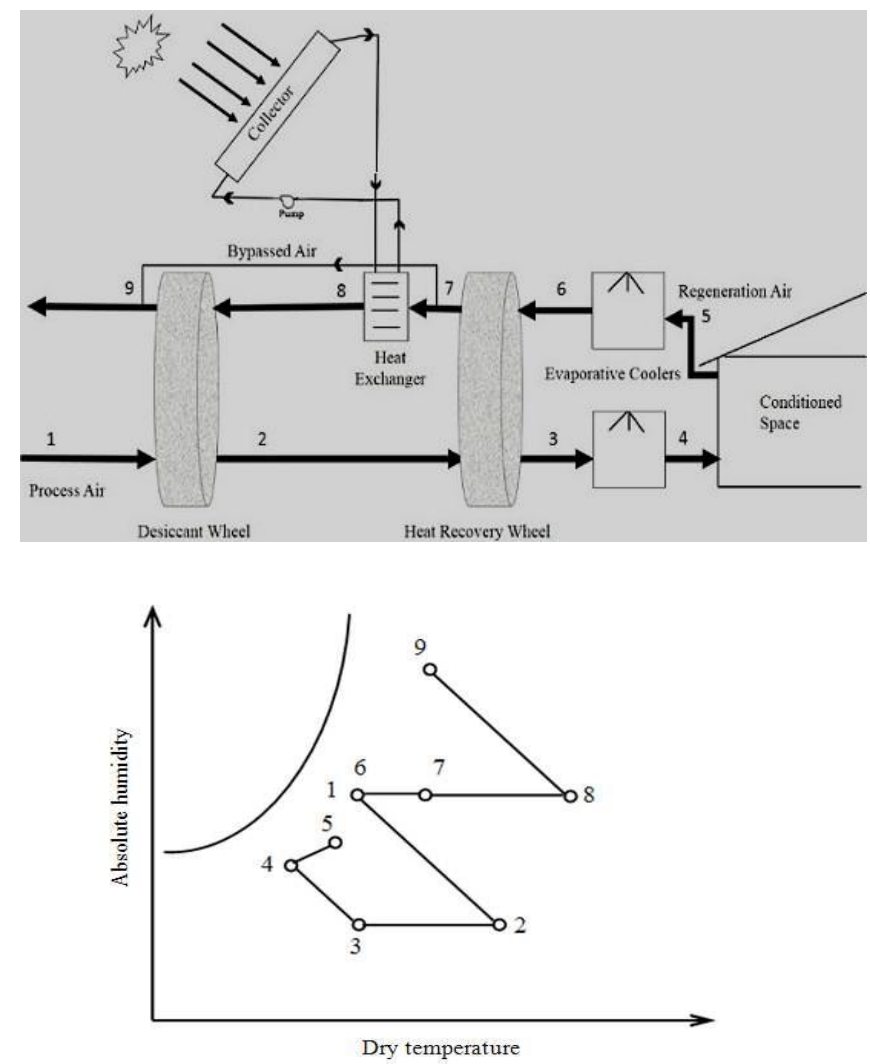

Fig. 1. Systematic diagram of solid desiccant cooling system and psychrometric processes. 
The relation for exergy efficiency can be written for the system shown in Fig. 1 as

$$
\eta_{\text {exergy }}=\frac{\text { exergy }_{\text {out }}}{\text { exergy }_{\text {in }}}=\frac{\dot{E}_{\text {cool }}}{\dot{E}_{\text {heat }}}
$$

where

$$
\begin{aligned}
& \dot{E}_{\text {cool }}=\dot{m}_{1}\left[\left(h_{1}-h_{4}\right)-T_{1}\left(s_{1}-s_{4}\right)\right] \\
& \dot{E}_{\text {heat }}=\dot{m}_{2}\left[\left(h_{8}-h_{7}\right)-T_{1}\left(s_{8}-s_{7}\right)\right]
\end{aligned}
$$

Similarly for the individual components (Desiccant wheel and heat recovery wheel) the exergy efficiency is given by

$$
\begin{gathered}
\eta_{D W}=\frac{\left[\left(h_{2}-h_{1}\right)-T_{1}\left(s_{2}-s_{1}\right)\right]}{\left[\left(h_{8}-h_{9}\right)-T_{1}\left(s_{8}-s_{9}\right)\right]} \\
\eta_{H R W}=\frac{\left[\left(h_{7}-h_{6}\right)-T_{1}\left(s_{7}-s_{6}\right)\right]}{\left[\left(h_{3}-h_{4}\right)-T_{1}\left(s_{3}-s_{4}\right)\right]}
\end{gathered}
$$

It can also be found as

$$
\eta_{\text {exergy }}=1-\frac{\dot{E}_{\text {destruction }}}{\dot{E}_{\text {in }}}
$$

For the two evaporative coolers the exergy efficiency relations can be written as

$$
\begin{gathered}
\eta_{E C 1}=1-\frac{\dot{E}_{\text {destruction, }, E C 1}}{\dot{E}_{3}} \\
\eta_{E C 2}=1-\frac{\dot{E}_{\text {destruction, } E C 2}}{\dot{E}_{5}}
\end{gathered}
$$

$\dot{E}_{3}$ and $\dot{E}_{5}$ are rate of exergy at state point 3 and 5 respectively.

The exergy efficiency of the solar collector can be given as

$$
\eta_{s c}=1-\frac{\dot{E}_{\text {destruction }, s c}}{\dot{E}_{7}}
$$

\section{RESULTS AND DISCUSSIONS}

The desiccant cooling cycle operating under ventilation cycle as shown in Fig. 1, is theoretically solved using silica gel performance curves and applying energy and mass balances at the corresponding points. The obtained values of temperatures (dry and wet bulb), and relative humidity at each state point after the thermodynamic analysis of the cycle are listed in Table II. The temperature of air at state point 5 and 8 represents required indoor temperature for human comfort and regeneration temperature, respectively. The built in functions of Engineering Equation Solver (EES) is used to obtain thermodynamic properties of water and moist air.

The values of effectiveness, exergy efficiency, and anergy for the system and its components are presented in Table III. The heat recovery wheel has low value of exergy efficiency $(40 \%)$ as well as low effectiveness $(52 \%)$. Both evaporative coolers have high value of effectiveness (92 and 89\%). Evaporative coolers 1 (EC1) has an exergy efficiency of $17 \%$ while this value is $56 \%$ for evaporative cooler 2 (EC2). The EC1 has lower exergy efficiency because of higher irreversibility in EC1 which happens because of the greater evaporation rate.

The heating source (solar collector) is considered to be operating at constant temperature. With this assumption of constant temperature the exergy efficiency of the solar collector is measured to be $51 \%$. The effectiveness value of desiccant wheel is low (53\%). The exergy efficiency of the desiccant wheel is found to be (74\%) which is good results as the maximum achieved exergy efficiency for this type of systems is about $85 \%$ as reported by Bulck et al. [14].

Smaller the exergy efficiency greater the value of anergy as it can be seen from the Table III. Desiccant wheel and solar collector shares the greater part of anergy with desiccant wheel having (32\%) of the total anergy and solar collector $(31 \%)$. The remaining $37 \%$ of anergy is accounted with heat recovery wheel $(17 \%)$ and evaporative coolers $(20 \%)$. These obtained results shows a good agreement with the experimental results obtained by the Kodama et al. [8]. They concluded from their experiments that major part of entropy generation is accompanied by desiccant dehumidifier and heating system.

TABLE II: TheORETICAlly CAlCUlated PROPERTIES OF THE DeSicCANT COOLING System

\begin{tabular}{ccccccc}
\hline \hline $\begin{array}{c}\text { State } \\
\text { point }\end{array}$ & $\begin{array}{c}\text { Dry bulb } \\
\text { temperature } \\
\left({ }^{\circ} \mathrm{C}\right)\end{array}$ & $\begin{array}{c}\text { Wet bulb } \\
\text { temperature } \\
\left({ }^{\circ} \mathrm{C}\right)\end{array}$ & $\begin{array}{c}\text { Humidity } \\
\text { ratio } \\
(\mathrm{kg} / \mathrm{kg})\end{array}$ & $\begin{array}{c}\text { Relative } \\
\text { humidity } \\
(\%)\end{array}$ & $\begin{array}{l}\text { Specific } \\
\text { enthalpy } \\
(\mathrm{kJ} / \mathrm{kg})\end{array}$ & $\begin{array}{l}\text { Specific } \\
\text { entropy } \\
(\mathrm{kJ} / \mathrm{kg}-\mathrm{K})\end{array}$ \\
\hline 1 & 42 & 28.2 & 0.0150 & 35.1 & 90.29 & 5.92 \\
\hline 2 & 62.3 & 30 & 0.0056 & 15.4 & 117.50 & 6.01 \\
\hline 3 & 34.3 & 18.9 & 0.0056 & 16.1 & 40.70 & 5.75 \\
\hline 4 & 17 & 15.1 & 0.0090 & 82.3 & 42.29 & 5.76 \\
\hline 5 & 30.3 & 26.1 & 0.0090 & 73.8 & 86.95 & 5.91 \\
\hline 6 & 26.5 & 23.4 & 0.0140 & 78.1 & 70.88 & 5.86 \\
\hline 7 & 49.8 & 35.6 & 0.0140 & 30.0 & 128.9 & 6.14 \\
\hline 8 & 120 & 50.8 & 0.0140 & 15.0 & 586.7 & 7.44 \\
\hline 9 & 90.3 & 70.2 & 0.0170 & 32.3 & 646 & 7.63 \\
\hline \hline
\end{tabular}


TABLE III: MEASURED ENERGY, EXERGY AND ANERGy DATA FOR THE SYSTEM AND ITS INDIVIDUAL COMPONENTS

\begin{tabular}{|c|c|c|c|c|}
\hline Component & Effectiveness (\%) & $\begin{array}{c}\text { Exergy efficiency } \\
(\%)\end{array}$ & $\begin{array}{c}\text { Anergy }\left(\dot{E}_{\text {destruction }}\right) \\
(\mathrm{KW})\end{array}$ & Anergy $\left(\dot{E}_{\text {destruction }}\right)(\%)$ \\
\hline Desiccant wheel & $53 \%$ & 74 & 0.130 & 32 \\
\hline Heat recovery wheel & 52 & 40 & 0.069 & 17 \\
\hline Evaporative cooler 1 & 92 & 17 & 0.062 & 15.1 \\
\hline Evaporative cooler 2 & 89 & 56 & 0.020 & 4.9 \\
\hline Solar collector & - & 51 & 0.127 & 31 \\
\hline System overall & - & 5 & 0.403 & 100 \\
\hline
\end{tabular}

The causes of the irreversibilities for the dehumidifier are identified by Bulck et al. [14]. These caused includes process and regeneration air mixing, difference of vapor pressure between regeneration air and matrix of desiccant, and heat transfer. The transfer of heat is the major cause of irreversibility in heat recovery wheel. The method adopted to provide the input heat determines the cause of irreversibility for heating system. Temperature difference $\left(T_{8}-T_{7}\right)$ is major factor for irreversibility for the heat source at constant temperature (ideal heat source).

The system has lower overall exergy efficiency (5\%). In order to approach the reversible COP, the entropy generation should be minimum for each component of the system. The process of entropy minimization should be started from the component having greater exergy destruction.

The exergy efficiency and COP of the system can be increased remarkdly, by minimizing the exergy destruction in desiccant wheel, heat recovery wheel, solar collector and evaporative coolers. Maclaine-cross [7] attempted to minimize the entropy generation by using wet surface heat exchanger instead of evaporative coolers.

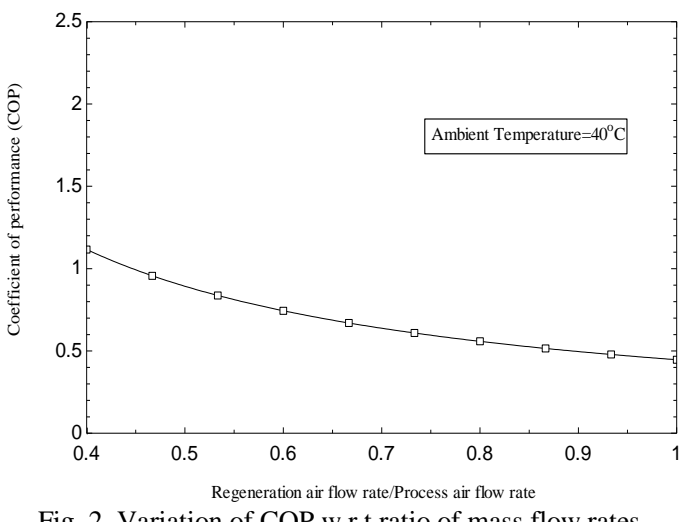

Fig. 2. Variation of COP w.r.t ratio of mass flow rates.

Fig. 2 and Fig. 3 show the variation of system COP with respect to regeneration to process air flow rate ratio and temperature of regeneration, respectively. The value of system COP increases as air flow rates ratio decreases as it can be observed from Fig. 2. The increase in COP with decrease in this ratio of air flow rates occurs because of decreases regeneration air flow rate which in turn decreases the required regeneration heat of the system as it can be seen from the Fig. 4, that as the ratio of mass flow rate increases or in other words mass flow rate of regeneration air increases, required regeneration heat increases too. The $\mathrm{COP}$ of the system decreases as the required regeneration temperature increase as shown in Fig. 3. The decrease in COP of the system occurs because of the regeneration temperature directly affects the required regeneration heat. The mass flow rates ratio and regeneration temperature plays an important role in system performance. Fig. 2, Fig. 3, and Fig. 4 can be used to optimize the values of mass flow rates ratio and regeneration temperature in required zone of operation to achieve the high performance of the system.

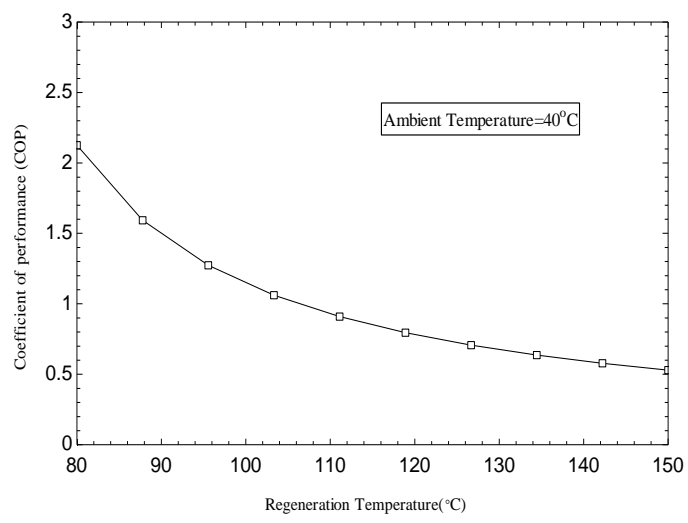

Fig. 3. Variation of COP w.r.t regeneration temperature.

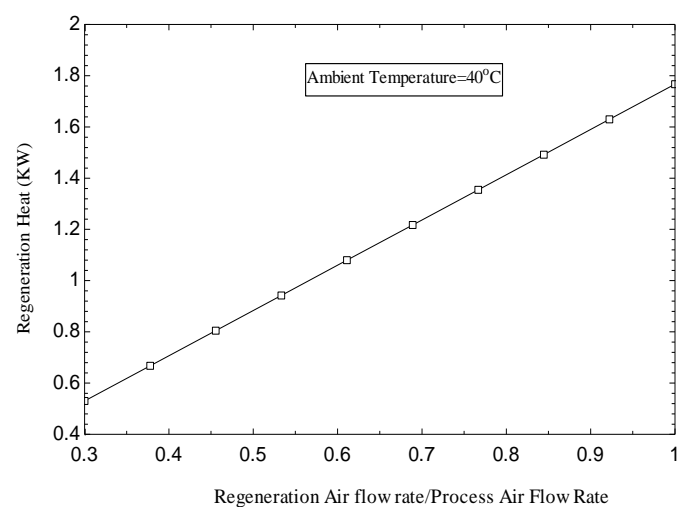

Fig. 4. Variation of regeneration heat w.r.t ratio of mass flow rates.

\section{CONCLUSIONS}

A theoretical model for solar desiccant cooling system (DCS) is developed to analyze the system performance based on energy and exergy. The analysis shows that an upper theoretical performance limit of the system can be determined from the exergy analysis. The energy analysis alone cannot be used to obtain this upper limit of performance. This exergy analysis shows the way to minimize the entropy generation by indicating the sites with maximum anergy or exergy destruction. The results show that desiccant wheel and solar collectors shares the major part of the exergy destruction because of the different irreversibilities. 
The effect of ratio between regeneration to process air flow rate and regeneration temperature on COP of the system has also been observed. The mass flow rates ratio and regeneration temperature directly affects the regeneration heat required which in turns affect the COP of the system. In order to obtain the best performance of the system, the values of these parameters need to be optimized.

\section{NOMENCLATURES}

$$
\begin{aligned}
& E \text { : specific exergy }(\mathrm{KJ} / \mathrm{Kg}) \\
& \dot{E} \text { : flow of exergy rate }(\mathrm{kW}) \\
& \dot{E}_{\text {destruction }} \text { : destruction of exergy rate }(\mathrm{kW}) \\
& \dot{E}_{i n} \text { : input rate of exergy }(\mathrm{kW}) \\
& \dot{E}_{\text {cool }} \text { : input work required for cooling }(\mathrm{kW}) \\
& \dot{E}_{\text {heat }} \text { : regeneration heat supplied }(\mathrm{kW}) \\
& h \text { : specific enthalpy }(\mathrm{KJ} / \mathrm{Kg}) \\
& h_{o} \text { : specific exergy at dead state }(\mathrm{KJ} / \mathrm{Kg}) \\
& \dot{m}_{1} \text { : mass flow rates of process air }(\mathrm{kg} / \mathrm{s}) \\
& \dot{m}_{2} \text { : mass flow rates of regeneration air }(\mathrm{kg} / \mathrm{s}) \\
& \dot{m}_{w} \text { : rate of moisture addition to the air }(\mathrm{kg} / \mathrm{s}) \\
& \dot{Q}_{c} \text { : rate of the heat removed }(\mathrm{kW}) \\
& \dot{Q}_{r} \text { : rate of heat of regeneration supplied }(\mathrm{kW}) \\
& s: \text { specific entropy }(\mathrm{KJ} / \mathrm{Kg}-\mathrm{K}) \\
& S_{o} \text { : specific entropy at dead state }(\mathrm{KJ} / \mathrm{Kg}-\mathrm{K}) \\
& S_{w} \text { : specific entropy of liquid water }(\mathrm{kJ} / \mathrm{Kg}-\mathrm{K}) \\
& T_{o} \text { : temperature at dead state }(\mathrm{K}) \\
& T \text { : temperature (K) }
\end{aligned}
$$

\section{Subscripts:}

\section{Greek Letters:}

$\varepsilon$ : effectiveness

$\eta$ : efficiency

\section{ACKNOWLEDGMENTS}

The authors would like to acknowledge the support provided by King Abdulaziz City for Science and Technology (KACST) through the Science \& Technology Unit at King Fahd University of Petroleum \& Minerals (KFUPM) for funding this work through project No. 10-ENE1372-04 as part of the National Science, Technology and Innovation Plan.

\section{REFERENCES}

[1] E. Van den Bulck, J. W. Mitchell, and S. A. Klein, "The use of dehumidifiers in desiccant cooling and dehumidification systems," $J$. Heat Transf., vol. 108, no. 3, pp. 684-692, Aug. 1986.

[2] J. J. Jurinak, J. W. Mitchell, and W. A. Beckman, "Open-cycle desiccant air conditioning as an alternative to vapor compression cooling in residential applications," J. Sol. Energy Eng., vol. 106, no. 3 pp. 252-260, Aug. 1984
[3] S. M. Krishna and S. S. Murthy, "Experiments on a silica gel rotary dehumidifier," Heat Recovery Syst. CHP, vol. 9, no. 5, pp. 467-473, 1989.

[4] S. Jain, P. L. Dhar, and S. C. Kaushik, "Experimental studies on the dehumidifier and regenerator of a liquid desiccant cooling system,' Appl. Therm. Eng., vol. 20, no. 3, pp. 253-267, Feb. 2000.

[5] P. Mavroudaki, C. B. Beggs, P. A. Sleigh, and S. P. Halliday, "The potential for solar powered single-stage desiccant cooling in southern Europe," Appl. Therm. Eng., vol. 22, no. 10, pp. 1129-1140, Jul. 2002.

[6] Z. Lavan, J.-B. Monnier, and W. M. Worek, "Second law analysis of desiccant cooling systems," J. Sol. Energy Eng., vol. 104, no. 3, pp. 229-236, Aug. 1982

[7] I. L. Maclaine-cross, "High-performance adiabatic desiccant open-cooling cycles," J. Sol. Energy Eng., vol. 107, no. 1, p. 102 1985.

[8] M. Pons and A. Kodama, "Entropic analysis of adsorption open cycles for air conditioning. Part 1: first and second law analyses," Int. J. Energy Res., vol. 24, no. 3, pp. 251-262, Mar. 2000.

[9] C. Borgnakke et al., Fundamentals of Thermodynamics, New York: Wiley, 2009

[10] M. J. Moran, Availability Analysis: Guide to Efficient Energy Use, 1st Edition. Prentice Hall, 1982.

[11] R. Yumrutaş, M. Kunduz, and M. Kanoğlu, "Exergy analysis of vapor compression refrigeration systems," Exergy Int. J., vol. 2, no. 4, pp. 266-272, 2002.

[12] M. Kanoglu, "Exergy analysis of multistage cascade refrigeration cycle used for natural gas liquefaction," Int. J. Energy Res., vol. 26, no. 8, pp. 763-774, Jun. 2002

[13] M. Kanoglu, I. Dincer, and M. A. Rosen, "Exergy analysis of psychrometric processes for HVAC\&R applications. (Heating, ventilation, and air-conditioning and refrigeration)," ASHRAE Trans. Jul. 2007.

[14] E. Van den Bulck, S. A. Klein, and J. W. Mitchell, "Second law analysis of solid desiccant rotary dehumidifiers," J. Sol. Energy Eng., vol. 110, no. 1, pp. 2-9, Feb. 1988

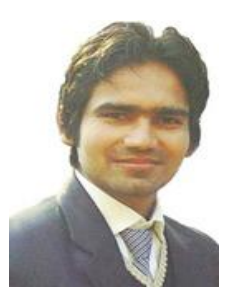

M. Mujahid Rafique was born in Punjab, Pakistan in March, 1989. He is currently pursuing his MS degree in mechanical engineering at King Fahd University of Petroleum and Minerals (KFUPM), Dhahran, Saudi Arabia. He received his B.E. degree with honours in mechanical engineering from University of Engineering and Technology, Lahore, Pakistan in August 2012.

Mr. Mujahid's main research focuses on development of clean and green energy systems. He worked on the use of renewable energy for air conditioning applications in his undergraduate program. His MS thesis topic is also related to solar thermal cooling. His main areas of interests are energy management, air conditioning, desiccant cooling, heat and mass transfer, and renewable energy technologies.

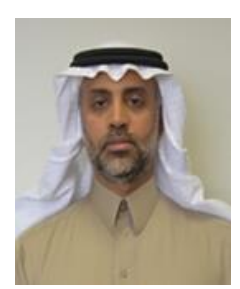

Luai Al-Hadhrami is an associate professor and director of Center for Engineering Research in the King Fahd University of Petroleum \& Minerals, Dhahran.

Dr. Luai Al-Hadhrami has received his Ph.D. degree in the thermo fluids area from the Mechanical Engineering Department of Texas A\&M University in 2002. He obtained his M.Sc. degree in mechanica engineering from KFUPM in 1997 in the area of thermo fluids. He has been actively involved in research of the fields of heat transfer and fluid flow in turbo machinery and energy management. During his work at KFUPM, Dr. Al-Hadhrami has gained industrial experience in turbo-machinery, designing, setting up and conducting various experiments for teaching and research. He has interest in computational modeling related to turbine heat transfer, gas and steam turbine power generation, retrofitting of gas turbine power plants to raise output and he is familiar with using commercial codes (Star-CD, Fluent, GTPRO), data acquisition system (Lab view) and liquid crystal technique. He has good experience in gas turbine heat transfer and related activities. He has published several technical papers in reputed journals and international conferences. He is part of several client funded energy related project (ECRA, SEC, GE ARMACO) at the university.

He is heading the activities to establish High Voltage and High Power Laboratory which will serve the Kingdom and GCC countries to enhance 
energy saving and power system reliability. It is expected to be established soon with a foreseeable investment of more than 200 million US\$.

Also, he is actively working to establish a Thermal Barrier Coating (High Temperature) Laboratory which will raise the efficiency of gas turbine in power generation industries by extending the life of the turbine components.

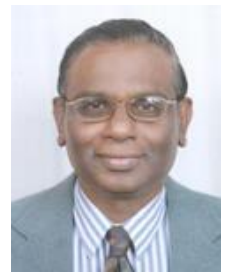

P. Gandhidasan is a professor of mechanical engineering at King Fahd University of Petroleum and Minerals (KFUPM), Dhahran, Saudi Arabia. He received his $\mathrm{PhD}$ degree in mechanical engineering from the Indian Institute of Technology, Madras, in 1979. He has over 35 years of teaching and research experience and has published over 100 technical journal/conference papers.

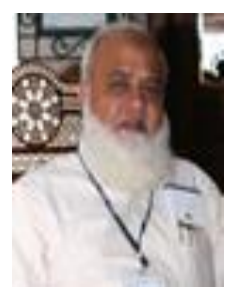

Shafiqur Rehman received Ph.D., M.S. and B.S. degrees in mechanical engineering from University of Pretoria, South Africa in 2012; King Fahd University of Petroleum and Minerals (KFUPM), Dhahran Saudi Arabia in 1985; and Aligarh Muslim University (AMU), Aligarh, India in 1981, respectively.

Shafiqur Rehman is a research engineer at Center for Engineering Research in Research Institute at KFUPM. He has more than twenty years of research experience in surface and upper air meteorology, wind and solar energy assessment, wind/pv/diesel hybrid power system design with and without battery backup, meteorological data measurements using 40 to 60 meter tall towers, optimization, concrete and concrete corrosion, corrosion management and costing, and recently has developed interest in geothermal power resources assessment and global warming issues and trending.

$\mathrm{He}$ has published and presented more than 150 research papers in international refereed journals and conferences. He has two patents awarded by US. Dr. Shafiqur Rehman has received CSIRO best-paper award for his research paper entitled, "Global review and synthesis of trends in observed terrestrial near-surface wind speeds: Implication for evaporation.

$\mathrm{He}$ has been invited as a keynote speaker in various international conferences and presented more than 20 papers in different international conferences. He has chaired and co-chaired technical sessions at international conferences and congress. He has been awarded distinguished researchers award in 2012 and 2006 by KFUPM. He is refereeing research papers for 20 journals related to his field of interest. He has more than 1600 citations excluding self and citation by all co-authors in Scopus with an h-index of 22 